\title{
Interpersonal Cooperation in Multicultural Working Context
}

\author{
Helena Karjalainen \\ Professor of Intercultural Management, Ecole de Management de Normandie/Normandy Business School \\ 9 rue Claude Bloch, 14052 CAEN Cedex, France \\ Tel: 33-2-3146-7878Ｅ-mail: h.karjalainen@em-normandie.fr \\ Richard Soparnot \\ Professor of Strategy and Management, Loire Valley University/CRESCEM/ESCEM - VALLOREM EA 6296 \\ Groupe ESCEM, 1 Rue Léo Delibes, BP 0535, 37205 Tours Cedex 3, France \\ Tel: 33-2-477-7168Ｅ-mail: rsoparnot@escem.fr
}

Received: September 9, 2011

Accepted: April 16, 2012

Published: June 1, 2012

doi:10.5539/ibr.v5n6p73

URL: http://dx.doi.org/10.5539/ibr.v5n6p73

\begin{abstract}
The cooperation process has hardly been studied in multicultural organisations. Empirical and theoretical studies have identified its functioning process by its nature or by its stimulating factors; however there is a lack of research concerning the interpersonal cooperation process in intercultural organisations. This research paper proposes an interpersonal cooperation model elaborated firstly in a mono-cultural working environment, which is then applied to an intercultural organisation in order to elaborate a cross-cultural model for cooperation. The model suggests that interpersonal cooperation is a dual process and based on a political dimension (a calculation process of individuals which can prevent cooperation) and identification dimension. Based on an empirical research method, the paper presents the application of the model through an inter-site case study including 30 interviews in an international company amongst 10 different nationalities. Moreover, the case study stresses that the political dimension of the model is not relevant in an intercultural context because the identification dimension prevails. The identification process reflects a strong organisational culture of the company Prometheus which has a human resource management focus on a common understanding of others where the national cultural differences become secondary (based on an anthropological conception of human beings). Finally, the theoretical implications of the study argue that interpersonal cooperation process is not the same in mono-cultural and intercultural organisations. It can also be concluded that managers should build a strong organisational culture in intercultural organisations and multiply common interpersonal projects in order to create a strong feeling of belonging to a work group and to a company.
\end{abstract}

Keywords: Interpersonal cooperation, Multicultural organisation, Social identification, Organisational culture

\section{Introduction}

Cooperation in organisations is at the heart of managerial and academic reflections. Understanding collective action in organisations challenges managers who try to coordinate team work in companies, but also academic researchers who wish to understand the nature, foundations and effects of interpersonal cooperation. If some recent empirical and theoretical studies contribute with new responses to this understanding (Bernoux, 1995; Zarifian, 1995; Dameron, 2003-2004), they nevertheless remain limited to mono-cultural work groups in organisations. Yet, the complexity of multicultural organisations and the difficulty to get employees representing different cultures to work together makes it necessary to complete more studies on the understanding of interpersonal cooperation in a multicultural working environment (Adler, 1986; Chevrier, 2000). According to Cox (1991) multicultural organisations refer to the degree to which an organisation values cultural diversity and is willing to utilise and encourage it. Organisations can diverse in terms of gender, race, ethnicity, and nationality.

The theoretical field of intercultural management is indeed characterised by the absence of empirical work allowing the comprehension of interpersonal cooperation in a multicultural working environment. Intercultural studies are mainly focused on the increasing diversity of the workforce and on the rising importance of teams and teamwork in the organisation and operation of organisations (O'Reilly, Williams \& Barsade, 1999). However previous studies still hang on the question of different mechanisms of interpersonal cooperation between cultures. The primary 
purpose of this study is to extend previous research and in particular to examine if cultural differences influence cooperation between group members in multicultural work groups.

This article, based on an empirical interpersonal cooperation model recently developed in a mono-cultural context (first part), seeks to explore its validity in a multicultural context (second part) through a study on five multicultural work groups. The research data analysed proposes then a model for interpersonal cooperation in a multicultural working environment (third part). Our results suggest particularly the importance of the question of social identification as a main mechanism for cooperation. Finally, a discussion of these results and suggestions for further research are presented.

\section{A Model for Interpersonal Cooperation in a Monocultural Working Environment}

According to De Bandt (1996), "cooperation consists in working together for the realisation of a common objective". In this sense, the individuals who work together accept to share their knowledge and their efforts in order to obtain an objective. Cooperation is then characterised by a common willingness to build something in common (Bercot \& De Coninck, 2003). As Capul (1998) states, "cooperation stays submitted to the only initiative of employees [...]. Cooperation can be characterised as a bundle of ties voluntarily built between employees [...]". But what is the nature for these ties?

Dameron $(2001 ; 2003 ; 2004)$ identifies two different dimensions for the cooperation process on the basis of her observation of several project groups in charge of developing new products in French car companies. Chédotel (2004) and Soparnot (2006) validate this typology following their empirical studies in French companies (including different activities such as the pharmaceutical industry and the car industry). These different studies confirm the existence of two factors for the interpersonal cooperation process. The first one, as qualified by Dameron is defined as a "complementary cooperation". This cooperative action is defined as a calculation process focused on the access to resources. In this cooperation process the strategy is linked to individuals' rationality. The second one, called a "communal cooperation", can be defined as belonging to a group where social exchanges characterise individuals' rationality.

\subsection{The Complementary Cooperation Process}

According to Crozier and Friedberg (1977), the cooperation process between individuals questions collective action and in particular its relationship with individual actions because cooperation can be seen as a tension between collective action and individual conflict forces. These authors try to understand how an articulation can be realised between the two realities: individual liberty and the existence of organised and coherent systems. Organisational strategical analysis (Crozier \& Friedberg, 1977) refutes theories which consider that individuals working in organisations can be assigned to a precise role with a rational behaviour. On the contrary, the individual uses a "limited rationality" which orientates his/her behaviour. This rationality is seen as an expression of a game strategy, a kind of totality of constraints to be discovered in a social and organisational context. The decisive element of behaviour is understood as a game of power and influence in which an individual takes part and through which he/she affirms his/her social existence. Here, the individual is no more subject to the rules but he/she is playing with them.

The relationships between individuals are considered above all as relations of power that secure to individuals the control of uncertain situations inherent to all systems of collective actions. The authors underline that "collective action is not an unfounded exercise [...]. The invented constructions of collective action can certainly redefine and rearrange problems; but neither their configurations nor their concrete modalities nor results can stay abstract of the property of the inherent structure; because the structure contains the most fundamental element which is uncertainty" (Crozier \& Friedberg, 1977). This is why individuals' behaviour must be analysed in terms of constraints and organisational opportunities.

The works of Crozier and Friedberg are the origins of the political approach to the cooperation process underlining individuals' power and division; interpersonal cooperation meaning in this context is a calculated behaviour. In this sense, cooperation means converging of interests, at least momentarily, linked to resources which are useful to the management of individuals' personal strategies. A calculated cooperation is founded on a social act of an action system containing opportunities and changing constraints. This is why cooperation can be defined as "an indeterminate, non programmable and non prescribed process" (Capul, 1998) because it depends first on individuals' political will. This political factor is not however the only explanation for the act of cooperation. It must be completed by an affective factor which can be described as a communal cooperation.

\subsection{The Communal Cooperation Process}

Mayo (1933) indicated the importance of groups in understanding individual's socialisation (Note 1). Here, the individual exists as a human being who demonstrates his/her identity through different relations he/she has inside a 
group. To the question "who am I?" the individual answers by referencing to a group (or groups) to which he/she assigns his/her membership (Pratt, 2003). (Group membership is therefore at the heart of an individuals' identification process. This has been described as the theory of social identity or TSI as developed by Tajfel (1978), Elsbach (1999), Tyler (1999) and Pratt (1998; 2003).

According to TSI, the feeling of belonging to a social group (professional, age, gender, etc.) and being part of this group characterises an individual's identity (Tajfel, 1978). Therefore, the identification process reveals three phenomena: the individual considers himself/herself as a member of a group; he/she adapts his/her characteristics/stereotypes to the group in question and acts in a manner that distinguishes his group from others (Turner \& Pratkanis, 1998). This kind of conformal behaviour and discrimination characterises individual's way to link to a group. The theory of social categorisation or TSC (Turner, 1987) extends then the TSI theory and refers to the method of elaboration of group borders (existence of ingroup and outgroup). According to TSC, the individual selects from the point of view of himself/herself social groups to which he/she gives prominent traits and to which he/she identifies himself/herself. These traits correspond to a prototype of the individual's values, rules and norms closest to his/her self concepts. In this sense, he/she keeps away from those groups whose prominent traits are too far from his/her conceptualisation of self. The TCS theory underlines however that the individual can arrange his/her conceptualisation of self in order to better correspond to another group's prototype. In other words, an individual's social identification is based on a perception of different groups (different categories) prominent traits and of a concordance of his/her own traits or conceptualisation of self.

The approach of the two theories (TSI and TSC) proposes then an interesting analysis on the interpersonal cooperation process (Chédotel, 2004). In terms of these theories, a collective final action (or cooperation) corresponds to a demonstration of a common identity in a group. Individuals develop and preserve a common identity when sharing the same objectives in a common interaction between members in a group (ingroup). Cooperation is then a way to be recognised as a member of a group (Tyler, 1999; Dubar, 2000). In the communal conception of cooperation acting together becomes fundamentally an identifiable resembling between individuals which characterises the group. The cooperation process is then the results of values, norms and common rules (prominent traits of a group) that depend on its existence and development. Therefore, cooperation is based on a rational identification (Dameron, 2004).

This double understanding of cooperation informs us about the foundations of cooperation and its nature (Figure 1). In a complementary approach, an individual's strategy explains the social link based on a particular interest and negotiation. In a communal approach, an individual's socialisation is the foundation for the cooperation relation in which an individual can reinforce his/her social identity. Moreover, these two cooperation logics are not mutually exclusive: they can be combined and mixed in order to translate the ambivalence of the cooperation phenomenon (Sainsaulieu, 1977; Dameron, 2004).

From now on, it will be examined how this interpersonal cooperation model, developed in a mono-cultural working environment, can be applied to a multicultural working context.

\section{Research Methodology}

This part of the paper will present our research methodology and the source of the data.

\subsection{Description of the Prometheus (Note 2) Company}

Prometheus is a global information company providing information for the financial services, media and corporate markets. While best known as one of the world's largest international multimedia news agencies, more than $90 \%$ of its revenues derive from financial products including equities, fixed income, foreign exchange, term deposits and commodities and energy markets around the world. The firm was created in London in the $19^{\text {th }}$ century, today it consists of more than 200 agencies in 130 countries. These agencies employ around 15000 members working in 19 languages, representing 123 different nationalities. The multicultural workforce represents professions such as journalists, engineers and administrative staff that work mainly in multicultural teams. The engineers are specialists in technical solutions and in programme installation (information software); administrative staff work as generalists or specialists with knowledge on risk management/solutions, treasury, asset management, investment banking and brokerage.

\subsection{Description of the Multicultural Work Groups}

\subsubsection{Team 1}

The first group differentiates itself from the others because it is the only permanently based group where all employees work together with their team supervisor. Their permanent working situation seems to be favourable in 
creating interactions between employees, in developing exchanges and facilitating the circulation of information, being both formal and informal in the group. The group also engages activities outside working hours.

The members of the group represent different cultures (American, Luxembourg, Belgian Flemish and French). The small number of team members facilitates the unity in this group and prevents members from the same nationality from getting together (this is the case in bigger groups). In this kind of small group, the spatial, social and cultural proximity helps to create certain common motivations, emotions and values: "I think it is very positive to work in a multicultural environment. We have no pressure between cultures. There are some stereotypes, of course, but the personality of the colleague is important, it goes beyond the national culture", says an account manager of Belgian Flemish nationality.

\subsubsection{Teams 2 and 5}

The other two groups present quite a different situation compared to the first group. These groups are composed of engineers, who work most of the time in client firms and are rarely present in their local agency. Because of this working situation, the interactions are very limited between employees. Interactions between engineers are also constrained by the habits they choose to adapt in their professional lives: "Communication is very formal between engineers, because they are between men”, explains the French team supervisor in Luxembourg. It seems indeed that engineers are less "talkative" by nature and prefer communicating by informal way (mails, mobile phones). These two groups are also bigger in quantity of employees and this allows the employees of the same nationality to get together: "The Luxembourg nationals like forming clans and they communicate in their native language. The same language unites them", says the French team supervisor. In spite of this mobile working situation of engineers, strong social ties can be observed with meetings after working hours or during lunch time.

As in the case of the first group, cultural differences seem to be balanced. Differences between engineers are more due to their profession than to different nationalities present in groups: "Between engineers, there are cultural differences linked to their profession. Some engineers that have graduated from the most famous schools consider themselves to be the elite of the profession and separate themselves”, states the French Marketing Manager in Paris. "Actually, we observe some stereotypes amongst engineers, for example, the French engineers get together and consider themselves as the best in the world", notes the Human Resources Director in Luxembourg.

\subsubsection{Teams 3 and 4 or the Virtual Teams}

Compared to the "traditional" work groups the virtual groups are not only complex in their functioning but also in their interactions. They face problems associated with working conditions in virtual teams, such as the problem of trust related to the distance between employees. Employees working far away from their collaborators and meeting each other rarely lack socialisation and cannot develop mutual trust like employees working together on a daily basis: "We have a problem of proximity; we seldom meet people with whom we work. Distance between people creates problems when they are of different origins. For example, it is difficult French and English employees to understand each other. How can you know that an Englishman never says no? His yes can mean no. It is easier to understand him when you face him", says the French team supervisor in Paris; "We would like to meet our colleagues to get to know each other", because our discussions on phone are of purely "academic" interest". In spite of efficient means of wireless communications (internet, mobile phones, videoconferences) that connect employees daily ("We communicate essentially through mails or videoconferences - our communication is $80 \%$ non verbal", states the team supervisor from the Brussels agency), these employees suffer from the physical distance from their collaborators. Obviously, the best technology cannot always replace the human presence in working relationships.

In the case of virtual teams, the culture variable can create more problems than in other teams: "Distance creates difficulties when you work with other cultures", as explains the French sales professional in the Paris agency. According to this team supervisor, face-to-face meetings are necessary to understand colleagues from different cultures. We need to specify that the culture variable seems to create more problems in the case of team 4 based in the Paris agency than in the case of team 3 based in Luxembourg where it is hardly noticed by the employees. We understand that this situation depends a lot on the difference based on the group management and on the characters of managing directors (participative management versus IT management).

\subsection{Research Methodology}

Our research methodology is based on an empirical approach close to ethnosociology (Chanlat, 2006). This approach directly contacts individuals and groups in the field by translating and analysing their perspectives, perceptions and interpretation of the surrounding environment. The methodology uses practical methods like ethnography to observe individuals. This is why we chose face-to-face interviews as an approach to meet individuals 
in their working places and to understand the complexity of the multicultural environment. Our methodology enabled us also to observe through our inquiry the cooperation process between multicultural employees. Our data was collected in Prometheus Company between May-October 2005 and includes 30 interviews. These interviews were semi-directive and based on a "theme-question" guide prepared in advance. The individual interviews lasted between 30 minutes and 1 hour each. The data has been analysed afterwards with the inter-site cases method suggested by Miles and Huberman (2003).

The empirical research data is based on observation of five multicultural work groups. These work groups represent the types of group existing in Prometheus. In order to obtain interviews useful to our research meetings with employees were carefully planned in advance with the support of the management. The employees were able to participate in our inquiry on a voluntary basis inside chosen multicultural work teams. Each employee was interviewed alone, not in group, so that he (she) could express himself (herself) freely without being influenced by the surrounding group. The interviews took place inside each agency in question in order to respect the social and cultural proximity of the working environment.

The members of these multicultural work groups were interviewed in three different countries (Belgium, France and Luxembourg) including the employees representing 10 nationalities (Algerian, American, Belgian, British, Dutch, French, German, Greek, Italian and Luxembourg nationals). Additionally, three human resources directors participated in this investigation (Note 3).

Our research process may be described as follows:

1) Interviews with multicultural work groups situated in Luxembourg and Brussels. These groups were:

a) A Sales Group composed of sales professionals. This team was based in Luxembourg.

b) A Client Training Group composed of engineers and training specialists.

c) A Professional Service Group composed of engineers working with client firms.

The Client Training group and Professional Service group were mobile teams that worked in Luxembourg and Brussels. Six employees were interviewed in these multicultural work groups.

2) Interviews with two virtual teams. These groups were:

a) A group of Risk Management professionals operating in eight countries. This team is managed by a Belgian Sales manager based in Luxembourg. The Manager coordinates the work of 20 employees in the team. Twelve members of the group were interviewed.

b) A group of marketing specialists. This was a group of 40 people based in Paris. The manager of this team was French. Four employees of this group were interviewed.

\section{Results and Discussion}

In the multicultural working environment, as studied in the Prometheus Company, the cooperation process is based mainly on the factor of a common identity and this can be explained in terms of the second dimension of the model, communal cooperation. The cooperation process corresponds to a common identity that is developed and preserved by all multicultural employees. This common identity can be characterised in terms of a favourable perception of diversity and of a favourable recognition of others shared by the employees. It can be explained through HRM policies that are orientated awards building internal common values in the company. This very cohesive organisational culture has a homogeneous role in reducing the negative effects of cultural differences.

\subsection{The Cooperation Process Based on a Common Identity}

"We are all the same" could be the slogan for the Prometheus employees. It seems that in the Prometheus Company there are no national identities but all identities converge to a common social identity developed inside the firm. Being a multicultural worker is seen here as a favourable factor that is encouraged by the identification process in the use of the same rules, values and norms inside work groups. This observation underlines the communal cooperation dimension and can be linked to the works of Tajfel (1978), Elsbach (1999), Tyler (1999) and Pratt $(1998,2003)$ and to the theory of social identity. Consequently, the employees adapt their behaviour to those of the group in order to resemble others. This suggests the relevance of the theory of social categorisation as a key element for analysing the cooperation process complementing the TSI.

\section{The favourable perception of diversity}

In our analysis on interactions between individuals in multicultural work groups we focused on the part of the culture variable in these interactions. We had several questions in our inquiry on perception of culture, on perception of stereotypes and on the acceptance of others. As result, we could conclude that nearly all employees interviewed in 
different agencies around Europe had a positive attitude towards diversity in teams. Only three employees from the Paris agency (Team 3) expressed reservations about this issue. Their reservations can be explained by the fact that they had recently joined the company after a merger with a French firm and that they had in particular many language problems in their working environment.

Considering stereotypes in groups, most of the employees recognised that there are lots of stereotypes in interactions between colleagues. Here again, the members of the Paris team experiencing language problems distinguish themselves from others, because they have less contact with their colleagues. In general, these members ignore stereotypes. According to the employees, meetings reveal stereotypes between colleagues: “The stereotypes are very present in our meetings, between French and Germans, for example, and between Belgians and Dutch. There is a belief that the Dutch are more professional than the Belgians", Belgian (French) national from the Brussels Agency. Many stereotypes are linked to the behaviour of individuals representing neighbouring countries. "We don't have any conflicts. Our Flemish and French speaking employees are the same at work. They stay very diplomatic. The Belgians are modest and the Dutch are more direct and transparent”.

Despite the cultural differences that reveal through stereotypes, the employees consider things very positively: "Working in a multicultural environment can only be positive, says marketing commercial of Algerian nationality from Paris agency. I think we must forget the stereotypes. We are not so different anyway. For me, it is a question of good sense. What counts is people, their lives, their reactions". The Sales director from Brussels underlines that working in a multicultural environment means learning all the time and adapting to situation: "Working in $a$ multicultural environment is not an obstacle, but it is a question of preparing and educating people. Managers must first be aware of cultural differences that exist between team members; afterwards it is a question of adaptation. For this, they must learn to know themselves and the others; they must go beyond stereotypes and share things with their collaborators also outside work".

Table 2 above shows that all the teams interviewed demonstrated a favourable perception of diversity in the company. For many, the multicultural working environment is a choice and enables a better understanding between oneself and the others. Many employees see it also as an opportunity to develop their language capacities and openness. Besides this favourable conception of diversity, we observed how the employees recognise others in groups. These interactions demonstrate employees' adaptability and facility in integration in the company because of the common identity developed between colleagues.

\section{The favourable recognition of others}

While considering the interview results on the perception of culture, on stereotypes or on the recognition of the others, we noticed an over-whelming tolerance that characterises the Prometheus employees. The impact of the positive attitude to diversity and the feeling of work satisfaction in this kind of environment are the factors that contribute to cooperation, argues Mrs Wagner, the Human Resources Director in Luxembourg: "We have noticed that the multicultural working environment increases employees' performance in their daily work". The consequences of this common attitude towards the multicultural environment can also be translated as a common behaviour that characterises Prometheus employees. As we noted above, this common behaviour gives a strong common identity to the whole staff of Prometheus, because it gathers together all different cultural identities and goes beyond national culture. The characteristics of this Prometheus culture (defined as an organisational culture according to Schein, 1992) can be described through four aspects as follows:

(1) Despite the strong common culture of the company, conflicts exist in the company (mostly related to language problems) but these situations are limited and rarely disturb cooperation in teams. Many employees think that the colleague's cultural background is not connected to the conflicts: "There are some problems in teams, but they are not related to cultures [...] they are more due to individual characters and personalities”, French supervisor of engineering team; "Everything depends on the personality of the colleague", Belgian engineer. Most of Prometheus employees prefer to talk about "momentary tensions" or "misunderstandings" instead of conflicts: "Sometimes, we have some difficulties in understanding each other"; "If we know each other's customs, there are less problems", team supervisor in Brussels; "I would rather talk about confusions or conflicts of interests related to the work not to the persons in question”, Dutch Sales professional.

(2) Even if the strong organisational culture amplifies the perception of the difference between nationalities, it does not prevent the presence of the stereotypes.

(3) In general, the employees' reactions confirm an overall satisfaction with their working environment. Different factors contribute to this: curiosity about other cultures and a sense of personal enrichment as a result of contacts with members of other cultures. 
(4) Our data shows that the organisational culture of Prometheus is based on a universal conception of human beings (in its anthropological meaning) which considers all individuals defined in origin by common biological characteristics. In other terms, as Hall (1971) puts it, this theory defines first a universal basis for understanding human beings physiologically, to which cultures confer a structure and a signification. Many employees interviewed shared the conception saying: "People are different, it is a question of personality", or "The personality of the colleague goes beyond his national culture". This kind of conception not only gives a favourable perception of diversity but also enables everyone to recognise their place in it. As result, it is more important for Prometheus employees to know other colleagues as individuals - by their personality and character - than to refer to their national culture, which in this case becomes a secondary factor ("The personality is more important than the national culture", Belgian (Flemish) Sales professional; "The personality is important, one's life, one's reactions", Algerian marketing professional).

In conclusion we believe that this organisational culture is (1) a common conception which does not exclude conflicts but limits their development; (2) contains still stereotypes but through a common conception, individuals act with more comprehension and tolerance; (3) seems to contribute to make internal integration easier, and (4) is the basis for the recognition of others and therefore a basis for acceptance and integration without discrimination. This organisational culture seems to be very tolerant and rational where the employees control different situations (even difficult ones). During the interview analysis we observed rationality and diplomacy in the responses given by employees. We think that this is due to the level of employees' education, to their social background and to their capacity in evolving in an international environment. We should not forget that the Prometheus multicultural environment is a result of a very careful recruitment process where Human Resources have chosen a certain type of person capable of working in this particular environment.

\subsection{The Anthropological Conception of Interpersonal Cooperation as a Management Tool}

The universal conception of human beings can be seen in the centre of the general policies for multicultural Human Resources Management in Prometheus. This policy is the basis for assembling cultural differences without discrimination. All management practices (recruitment, intercultural training/coaching and conflict management (Note 4)) and tools (recruitment tests, different intercultural training programmes, participative management and mediation) contribute to promote the organisational culture and the acceptance of the multicultural environment in the company. As the study reveals, HRM operates on different levels in the organisation: (1) on an organisational level: it seeks to assemble differences (different cultures and professions) through "smart working" policies by arranging favourable working conditions; (2) on a human resources management level: where it applies different practices and tools that contribute to cooperation between cultures; and (3) by constructing an organisational culture that aims to gather together different cultures and different cultural identities (to promote a global common identity). Due to the strong organisational culture, there seems to be fewer conflicts in the firm and as noted above; these are not usually connected to any particular culture. They are related more or less to different personalities or characters. This common identity characterises Prometheus employees interviewed in six different agencies in Europe.

In other words, Prometheus promotes behaviour that leads to goal congruence. It aims to obtain a maximum cooperation in teams, by respecting all differences. This approach seeks to integrate employees into a global system (Note 5). It is transmitted to the staff through organisational learning (Argyris \& Schön, 1978) and through groups (Mayo, 1933) which have an important role in identification, learning and control. "Working in teams is important, because it allows sharing the same information; it binds everybody to contribute to the team performance in order to obtain the same result; it functions through common objectives that all members must obtain", Human Resources director in Luxembourg. According to Brechet (1997), workers, individuals and groups, learn through organisational learning, they create and maintain new models and behaviours with their affective, cognitive and relational components. Our empirical study shows that a common behaviour can become also a source of motivation for employees and can contribute to cooperation in teams - to cooperate is a way of being recognised as a member of a group (Tyler, 1999; Dubar, 2000). In other words, once cultural differences are respected and well integrated to the system, the cultural factor is an accelerator for cooperation. "Actually, when you come into contact daily with individuals representing different nationalities, it is a permanent work of research on yourself. [...] Employees working in this kind of multicultural environment, develop their openness to differences, accepting more easily for example introduction of new materials for work, new projects, new types of management and above all are capable of changes inside our organisation”, Human Resources director in Luxembourg.

\section{Conclusion}

There are few studies of the cooperation process in multicultural organisations. This paper examines the interpersonal cooperation process in a multicultural working environment through an inter-site case study. It is based 
on an empirical cooperation model validated in a mono-cultural company, it seeks to explore in what extent this model can be applied to an international company.

Our study shows that in the case of Prometheus the interpersonal cooperation process is founded on the factor of a common identity and therefore can be explained in terms of the second dimension of the cooperation model by communal cooperation. The five multicultural work groups studied demonstrate a high level of cooperation despite their differences in intensity of interactions, group management and conflict management. The end result corresponds to a common identity that is developed and preserved in the company through efficient Human Resources Management. By respecting all cultural differences, goal congruence is privileged. Our study extends previous research on the interpersonal cooperation process because it underlines the primary role of the identification factor in interpersonal cooperation between multicultural employees. Therefore, it seems clear that cultural diversity in work groups influences cooperation between members by intensifying the role of the social identification dimension.

Broadly, this study provides an example of interpersonal cooperation in an international context that practitioners can apply in diverse work groups. In particular, managers and members of international teams can take comfort in knowing that a favourable perception of diversity and the recognition of others facilitates integration and increases the satisfaction of multicultural employees in a company. Therefore, there is also a basis for expecting less conflict situations in a company founded on cultural differences. For this, the role of the HRM policies developing common values is important and maintains interpersonal cooperation in the multicultural organisation. Anticipating such a possibility in international organisations helps managing cultural differences successfully.

Due to the scale of the study it would be difficult to generalise our theoretical and managerial findings. Further research should be conducted to determine if our conclusions are valid in wider context. A further point concerning future research is that it would be necessary to enlarge the study beyond Europe to see if our conclusions can cover the whole Prometheus organisation in America, Asia and the Middle East, because our actual conclusions are based on Prometheus' European agencies. What would be the results if the rest of the world was included? Would the influence of other cultures change the global human resources management attitude of Prometheus, or could we still conclude on the efficiency of Prometheus management process and its tools. In the longer term, it would be possible also to examine if some of the Prometheus management tools and practices can be transferred to other international companies.

\section{References}

Adler, N. (1983). Organizational Development in a Multicultural Environment. Journal of Applied Behavioral Science, 19(3), 349-365. http://dx.doi.org/10.1177/002188638301900311

Adler, N. (1986). International Dimensions of Organizational behaviour. Boston, MA: PWS-Kent Publishing Company.

Argyris, C., \& Schön, D. (1978). Organizational learning. Reading, MA: Addison-Wesley.

Bercot, R., \& De Coninck, F. (2003). Que devient le travail collectif dans des groupes entrecroisés et transitoires. Gérer et comprendre, 72, 69-78.

Bernoux, P. (1995). La sociologie des entreprises. Paris: Edition Seuil.

Brechet, J.-P. (1997). Les structures: leur importance, leur inertie, leur flexibilité. Cahiers 1997. University of Nantes, 17-31.

Capul, J-Y. (1998). Des organisations transversales à la coopération dans l'entreprise. Les cahiers français, 287, 57-65.

Chanlat, J.-F. (2006). La recherche en gestion et les méthodes ethnosociologiques. dans P. Roussel et F. Wacheux, Management des ressources humaines, Méthodes de recherche en sciences humaines et sociales. Bruxelles, De Boeck, 159-175.

Chédotel, F. (2004). Avoir le sentiment de faire partie d'une équipe: de l'identification à la coopération. Management, 7(3), 161-193.

Chevrier, S. (2000). Le management des équipes interculturelles. Paris: PUF.

Cox, T. H. (1991). The Multicultural Organization. The Executive, 5(2), 34-48. http://dx.doi.org/10.5465/AME.1991.4274675

Crozier, M., \& Friedberg, E. (1977). L'acteur et le système. Paris: Edition Seuil. 
Dameron, S. (2001). Les deux conceptions du développement des relations coopératives dans l'organisation. AIMS Conference, Québec, Canada.

Dameron, S. (2003). Structuration de la coopération au sein d'équipes projet. AIMS Conference, Sfax, Tunisia.

Dameron, S. (2004). Opportunisme ou besoin d'appartenance? La dualité coopérative dans le cas d'équipes projet. Management, 7(3), 137-160.

De Bandt, J. (1996). Coopération, accords interentreprises, concurrence. In J-L. Ravix (Ed.), Coopération entre les entreprises et organisations industrielles (pp. 195-229). Paris: CNRS Edition.

Dubar, C. (2000). La crise des identités. L'interprétation d'une mutation. Paris: Presses Universitaires de France.

Elsbach, K. (1999). An expanded model of organizational identification. Research in organizational behaviour, 21, 163-180.

Hall, E. T. (1971). La dimension cache (Hidden dimension). Paris: Edition Seuil.

Lewin, K. (1959). Psychologie dynamique. Paris: PUF.

Mayo, E. (1933). The Human Problems of an Industrial Civilization. New York: Mac Milan.

Miles, M., \& Huberman, M., (2003). Qualitative Data Analysis, An Expanded Sourcebook. Brussels: De Boeck.

O’Reilly, C. A., Williams, K. Y., \& Barsade, S. (1999). The Impact of Relational Demography on teamwork: when differences make a difference. Academy of Management Proceedings, Chicago.

Pratt, M. G. (1998). To Be or Not to Be? Central Questions in Social Identification. In D. A Whetten \& P. C. Godfrey (Eds.), Identity in organizations: Building Theory Through Conversations (pp. 171-207). Sage Publications: Thousand Oaks.

Pratt, M. G. (2003). Dinsentangling Collective Identities. In J. T. Polzer (Ed.), Research on Managing Groups and Teams (5: Identity Issues in Groups, pp. 161-188). Greenwich: JAI Press.

Sainsaulieu, R. (1977). L'identité au travail, Les effets culturels de l'organisation. Paris: Presses de la FNSP.

Schein, E. H. (1992). Organizational Culture and Leadership. San Francisco: Jossey-Bass Publishers.

Soparnot, R. (2006). La coopération inter-individus: le cas de la gestion de projet dans le secteur automobile. $15^{\text {ème }}$ Congrès de l'Association Internationale de Management Stratégique (AIMS), Annecy.

Tajfel, H. (1978). Social Categorization, Social Identity and Social Comparisons. In H. Tajfel (Ed.), Differentiation Between Social Groups: Studies in the Social Psychology of Intergroup Relations (pp. 61-76). London: Academic pressn.

Turner, J. C. (1987). A self-categorization theory. In J. C. Turner, M. A. Hogg, P. J. Oakes, S. D. Reicher \& M. S. Wetherell (Eds.), Rediscovering the social group: A self-categorization theory (pp. 42-67). Oxford, England: Blackwell Publishers.

Turner, M. E., \& Pratkanis, A. R. (1998). A social Identity Maintenance model of Groupthink. Organizational behaviour and Human Decision Process, 73(2/3), 210-235. http://dx.doi.org/10.1006/obhd.1998.2757

Tyler, T. R. (1999). Why people cooperate with organizations: an identity-based perspective. Research in Organizational Behaviour, 21, 241-246.

Zarifian, P. (1995). La nouvelle productivité. Paris, Edition L'harmattan.

\section{Notes}

Note 1. This conception of human behaviour is also defended by Emile Durkheim. For Durkheim a human being is a passive homo sociologicus; his behaviour is a consequence of social reasons. See also Raymond Boudon in «La logique du social» where this author proposes a similar discussion.

Note 2. The real name of the company will not be revealed in order to preserve confidentiality.

Note 3. The Global Human Resources Director from London, responsible for three continents, of British nationality; the Director for the Paris agency, of French nationality and the Director for the Luxembourg agency, also of French nationality.

Note 4. The conflict management policy is very clear for the managers; they have to know their team members and manage them (as stated by the Global Human Resources Director from headquarters in London).

Note 5. For Adler (1983), this kind of organisation is called "synergistic organisation". It recognises cultural differences and their consequences. 
Table 1. Questionnaires

For our interviews with different employees working in these five different multicultural work groups, we established a questionnaire containing questions on:

(1) work organisation in multicultural teams;

(2) perception of culture in teams;

(3) exchanges and communication between team members, extra professional activities;

(4) conflicts between team members;

(5) employees' involvement in their working environment.

While meeting Human Resources directors, a variant questionnaire were introduced containing questions on:

(1) staff management;

(2) work organisation in Prometheus;

(3) cultural factor in the company;

(4) management policies in respect of the multicultural workforce (recruitment; training, etc.). The aim of these interviews was to understand the role of the HRM function in the management of the company.

Table 2. Multicultural work group interactions

\begin{tabular}{|c|c|c|c|c|c|}
\hline Teams & Team management & Exchanges & Conflicts & $\begin{array}{c}\text { Perception of } \\
\text { multicultural work } \\
\text { environment }\end{array}$ & Consequences \\
\hline Team 1 & $\begin{array}{l}\text { Participative team } \\
\text { management and the } \\
\text { proximity of the } \\
\text { team manager }\end{array}$ & $\begin{array}{l}\text { Team cohesion and stable } \\
\text { team work }\end{array}$ & $\begin{array}{l}\text { Minor conflicts or } \\
\text { none }\end{array}$ & $\begin{array}{l}\text { Favourable perception of } \\
\text { diversity; } \\
\text { Favourable recognition } \\
\text { of others }\end{array}$ & $\begin{array}{l}\text { Facility in integration; } \\
\text { Recognition of others; } \\
\text { Overall satisfaction and } \\
\text { motivation }\end{array}$ \\
\hline $\begin{array}{l}\text { Teams } \\
2 \text { and } 5\end{array}$ & $\begin{array}{l}\text { Remote management } \\
\text { by supervising } \\
\text { managers }\end{array}$ & $\begin{array}{l}\text { Mobile } \\
\text { employees/engineers } \\
\text { working in the field }\end{array}$ & $\begin{array}{l}\text { Many absences from } \\
\text { office and less } \\
\text { meetings between } \\
\text { colleagues }\end{array}$ & $\begin{array}{l}\text { Favourable perception of } \\
\text { diversity; } \\
\text { Favourable recognition } \\
\text { of others }\end{array}$ & $\begin{array}{l}\text { Facility in integration; } \\
\text { Recognition of others; } \\
\text { Overall satisfaction and } \\
\text { motivation }\end{array}$ \\
\hline Team 3 & $\begin{array}{l}\text { Remote management } \\
\text { by mutual adjustment } \\
\text { (and team building) }\end{array}$ & $\begin{array}{l}\text { Social relationship } \\
\text { characterized by distance }\end{array}$ & $\begin{array}{l}\text { Yes, but these can } \\
\text { be managed and } \\
\text { they do not disturb } \\
\text { cooperation }\end{array}$ & $\begin{array}{l}\text { Favourable perception of } \\
\text { diversity; } \\
\text { Favourable recognition } \\
\text { of others }\end{array}$ & $\begin{array}{l}\text { Facility in integration; } \\
\text { Recognition of others; } \\
\text { Overall satisfaction and } \\
\text { motivation }\end{array}$ \\
\hline Team 4 & $\begin{array}{l}\text { Remote management } \\
\text { via IT solutions }\end{array}$ & $\begin{array}{l}\text { Social relationship } \\
\text { characterized by distance } \\
\text { and distant manager; } \\
\text { sometimes difficult } \\
\text { exchanges }\end{array}$ & $\begin{array}{l}\text { Yes, but can be } \\
\text { managed }\end{array}$ & $\begin{array}{l}\text { Favourable perception of } \\
\text { diversity; } \\
\text { Favourable recognition } \\
\text { of others }\end{array}$ & $\begin{array}{l}\text { Facility in integration; } \\
\text { Recognition of others; } \\
\text { Overall satisfaction and } \\
\text { motivation }\end{array}$ \\
\hline
\end{tabular}

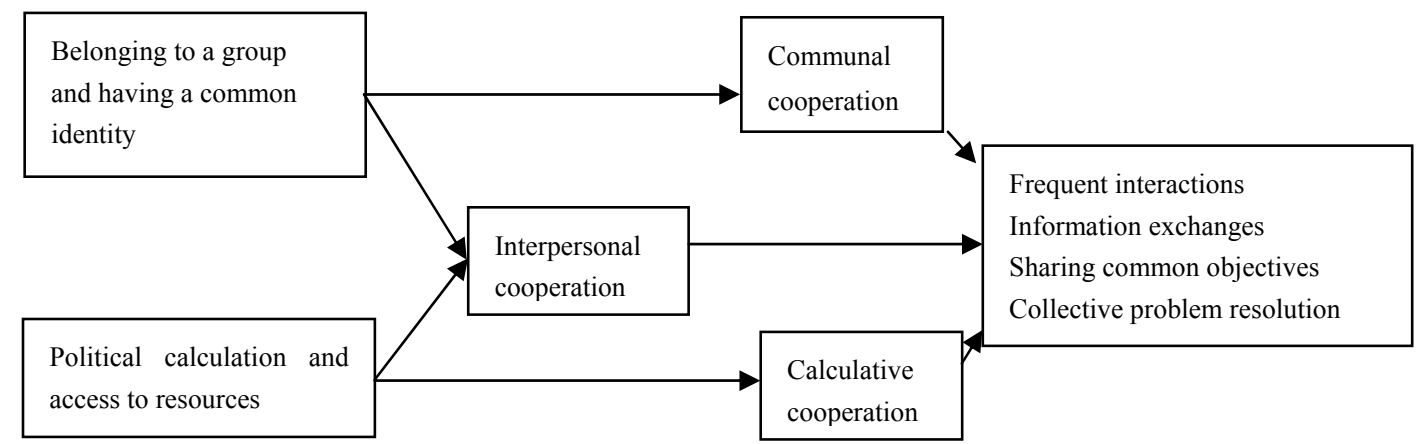

Figure 1. The interpersonal cooperation model in a mono-cultural context

Source: Chédotel (2004), Soparnot (2006). 